change of weather conditions. To study temporal and spatial dependences in behavior of atmospheric radon, thoron and their decay products was organized continuous automated radon monitoring, which started in 2011 with help of radiometer of radon isotopes and their decay products (SARAD GmbH, Germany). The analysis of seasonal variations of radon activity concentration in the ground atmosphere revealed maximum in spring-summer period and minimum in winter. In diurnal variations minimum appears afternoon and maximum - before noon. These results are in a good agreement with results of other radon investigations. The analysis of changes of equilibrium coefficients between radon and its decay products showed that the annual average value was 0.2 (0.25 in March-April, 0.12 in May, and 0.27 at the end of September). Dynamics of $F_{R n}$ in 2011 is shown in Figure 1a (spring season) and 1b (summer-autumn season). Analysis of the $F_{R n}$ coefficient dynamics shows that its instantaneous (average within 2 hours - red line) values can vary quite widely from 0 to 1 . Significant correlations were revealed between activity concentrations of radon, thoron and some of their short lived decay products at synoptic scale. Other interesting results of our investigation are also reported.
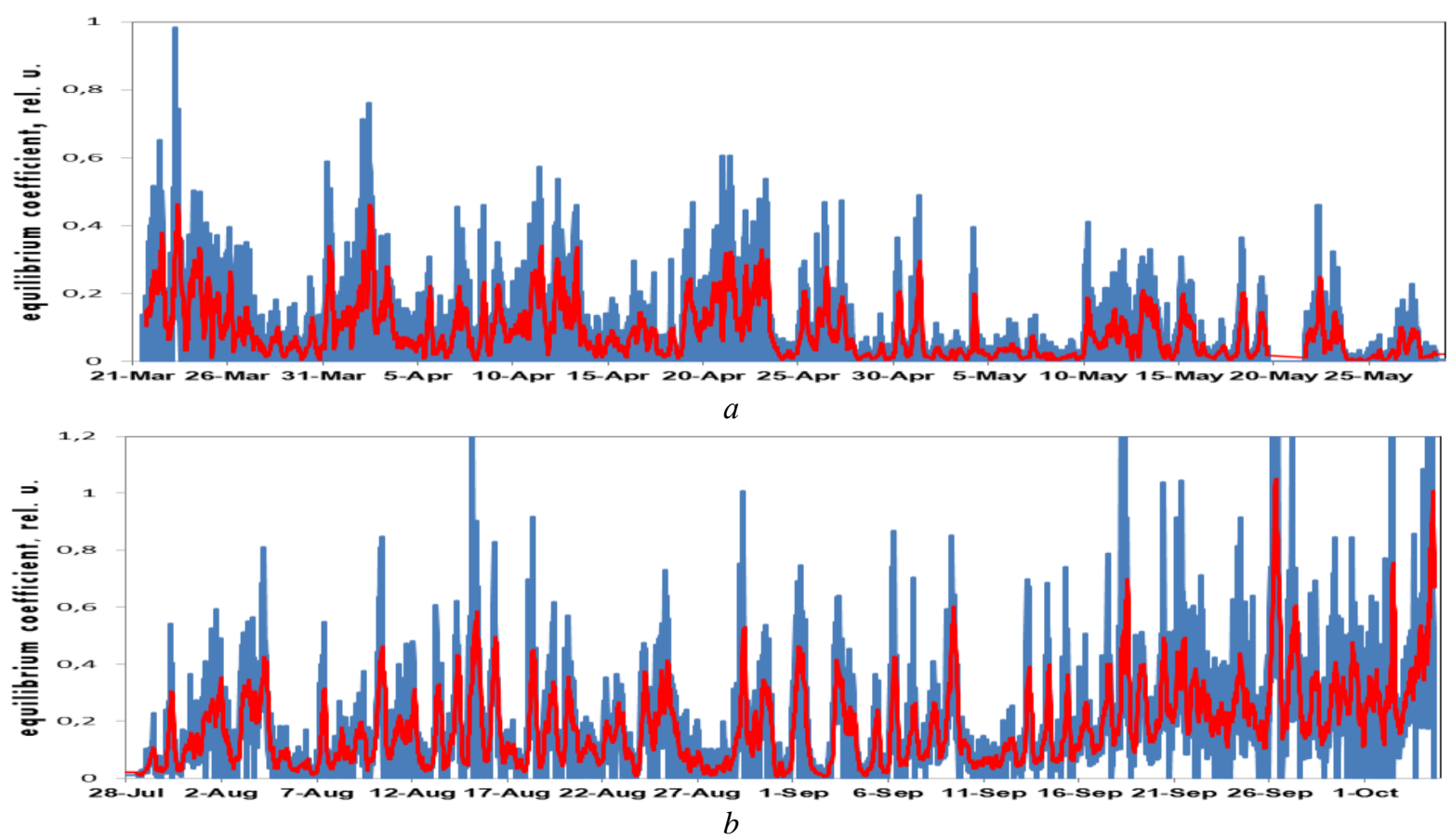

Figure 1. Dynamics of $F_{R n}$ in 2011: a) in spring; $b$ ) in summer-autumn

Supported by Federal Target Program № 14.575.21.0105

\title{
REFERENCES
}

1. Iakovleva V.S., Karataev V.D. Spatial and temporal variations of radon concentration in soil air // Radiation Measurements. - 2001. - Vol. 34 (1-6). - p. 501-504.

\section{MAGNETRON SPUTTERING SYSTEM}

\section{A.V. Lazarev, M.A. Andreeva, U.A. Smirnova}

National Research Politechnic University,

Russia, Tomsk, Lenina avenue 30, 634050

\section{E-mail: Alefantiy@mail.ru}

Thin film coatings have wide application as strengthening, reflective, conductive and dielectric coatings. One of the directions of vacuum-plasma technologies is the deposition of thin film coatings [1]. We consider the technology 
of application based on the use of magnetron sputtering system. The advantages of magnetron sputtering systems are even processing of flat surfaces with large area; the available gases used by the system; simplicity of design.

\section{MAGNETRON SPUTTERING SYSTEM OPERATION}

Coating formation is done with sputtering of the target by ions of the working gas in the abnormal glow discharge. The principle of operation of magnetron sputtering system is shown in figure 1. The main elements of MSS are cathode target, anode, magnetic system. The lines of force are closed between poles of magnetic system. The surface of target is placed between the points of entry and exit of the force lines of the magnetic system. The surface is sprayed actively and takes the form of closed track 6 . The geometry of track is determined by the form of poles of the magnetic system. The water is supplied in the body of magnetron sputtering system to cool the target [2].

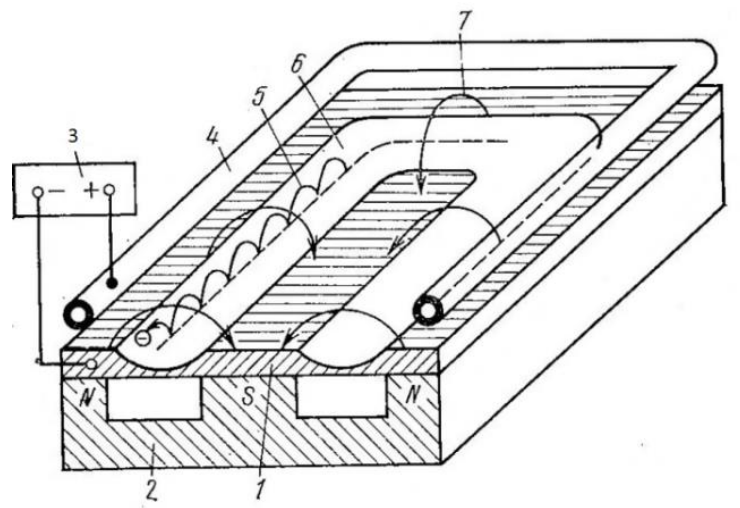

1 - cathode target; 2 - magnetic system; 3 - power supply unit; 4 -anode; 5 -trajectory of the electrons; 6 area of erosion of the cathode surface; 7 -force lines of magnetic system.

Figure 1. Magnetron sputtering system

The magnetron sputtering system is placed in a vacuum chamber. The system is electrically isolated from the chamber and the equipment. Working gas is supplied in the chamber after pumping out the air volume. Magnetic trap facilitates the ignition of the discharge, providing electron density greater than in the remaining volume.

\section{REFERENCES}

1. Krivobokov V. P., Sochugov N. S., Solovyov A.A. Plasma coverings (methods and equipment): The manual Tomsk: Publishing house of TPU, 2008. - 104 p.

2. Danilin B. S., Syrchin V. K. Magnetron sputtering system - M.: "Radio and communication", $1982-72$ p.

\section{COMPUTER MODEL OF THE «ASTRA» PULSED ELECTRON ACCELERATOR}

\section{A. Serebrennikov, I. S. Egorov}

National Research Tomsk Polytechnic University,

Russia, Tomsk, Lenina ave., 30, 634050

E-mail: smakk_22@mail.ru

Paper shows the process of creating of computational model for a pulsed electron accelerator "ASTRA" [1] (accelerating voltage up to $460 \mathrm{kV}$, beam current pulse duration of $75 \mathrm{~ns}$ (FWHM), pulse energy of up to $10 \mathrm{~J}$ for pulse repetition rate of up to $50 \mathrm{pps}$ ). Multisim software was used for electrical processes simulation.

The computational model is based on a schematic diagram of the accelerator, complemented with equivalent constructive elements of the accelerator - the parasitic inductance and capacitance. When the amplitude of the voltage pulse is $400-460 \mathrm{kV}$, the energy up to $20 \%$ of total can be accumulated by parasitics. The values of the parasitic 